\title{
Motivação e expectativas de alunos iniciantes de língua francesa
}

\author{
Andréa Emiliana Fernandes Santos ${ }^{1}$
}

\begin{abstract}
Resumo: $\mathrm{O}$ artigo em questão tem como proposta apresentar a motivação e as expectativas de 20 alunos aprendizes de francês, como língua estrangeira, em uma turma de francês oferecida em um centro de idiomas de uma universidade pública mineira. $\mathrm{O}$ instrumento para a coleta de dados foi o questionário aplicado aos alunos participantes, na intenção de elencar as motivações e as expectativas dos aprendizes no início do curso. Acreditamos que a motivação tem um papel importante no sucesso ou fracasso da aprendizagem. Por isso, identificar o que motiva ou desmotiva os aprendizes e suas expectativas neste processo foi tão relevante para o professor adequar sua aula ao público.
\end{abstract}

Palavras-chave: Motivação. Aprendizagem de língua estrangeira. Francês

\section{French 101 students' motivations and expectations}

Abstract: This article aims to present the motivation and expectations of 20 students learners of French as a foreign language, in a French class offered at a language center of a public university in Minas Gerais. As an instrument for data collection we used a questionnaire applied to the participating students in order to list their motivation and expectations at the beginning of the course. We believe that the motivation plays an important role in the success or failure of learning. Therefore, identifying what motivates or discourages learners and their expectations in this process was particularly relevant for teachers to adapt their classes to the public.

Keywords: Motivation. Foreign language learning. French

\section{INTRODUÇÃO}

Este artigo é o recorte de uma dissertação de mestrado que objetivou identificar expectativas dos alunos em relação ao estudo da língua francesa (LF). Os dados para análise foram coletados em um centro de idiomas de uma universidade pública mineira, no primeiro dia de aula, de uma turma de francês escolhida pelo maior número de alunos participantes. Foi aplicado aos alunos matriculados nesse curso um questionário que fez parte da pesquisa de mestrado da professora pesquisadora do estudo. A seguir, apresentaremos, o arcabouço teórico utilizado para o embasamento da investigação. Depois, faremos a discussão teórica baseada em autores como Gardner e Lambert (1972), Dörnyei (2001), dentre outros, que enfocam a

\footnotetext{
1 Professora contratada da Central de Línguas da Universidade Federal de Uberlândia (UFU) e mestre em Linguística Aplicada ao ensino e aprendizagem de Língua Estrangeira pelo Programa de Pós-graduação em Estudos Linguísticos do Instituto de Letras e Linguística da UFU. E-mail: andreaproffran@yahoo.com.br.
} 


\section{ITIFRARINS REFLECTIONIS}

Revista Eletrônica de Graduação e Pós-Graduação em Educaçāo

motivação. Em seguida, descreveremos a metodologia e, por fim, discutiremos os dados obtidos por meio do questionário respondido pelos alunos.

Os resultados da pesquisa em questão poderão ajudar os professores a refletir sobre a importância de se estudar a motivação inicial dos alunos e suas expectativas quanto à aprendizagem de uma língua estrangeira (LE).

\section{MOTIVAÇÃO}

Considerando que o presente estudo buscou investigar a motivação dos alunos participantes de um curso de francês, faz-se necessário definir, primeiramente, o conceito de motivação. Pinillos (1975) explica que a palavra motivação é derivada do latim "motus" e designa, na linguagem corrente, raiz dinâmica do comportamento, isto é, fatores determinantes internos, mais do que externos ao sujeito, que de dentro para fora, o incitam à ação.

De acordo com Pintrich e Shunk (1996, apud JACOB, 2002, p. 35), o termo motivação, de origem latina, é derivado de "movere" (mover, induzir). Os autores descrevem a motivação como "um processo por meio do qual atividades com metas direcionadas são instigadas e sustentadas" (PINTRITCH; SCHUNK, 1996 apud JACOB, 2002, p. 35).

De acordo com Dörnyei (2001), existem três aspectos do comportamento humano que nos ajudam a entender o conceito de motivação, são eles: a escolha de determinada ação, a persistência no desempenho desta ação e o esforço nela despendido. Esses aspectos nos fazem compreender que a motivação é responsável pelo por que os indivíduos estão decididos a fazer algo, por quanto tempo eles dispõem-se na execução de uma atividade, e o quão dedicados a ela estarão. Jacob (2002, p.36) relata que esses autores consideram os alunos motivados quando eles se interessam pelas atividades, se sentem capazes, esforçam-se, persistem e usam estratégias cognitivas para desenvolverem as tarefas. Quanto aos professores, eles estão motivados quando acreditam que podem auxiliar os alunos no aprendizado, gastando tempo extra em planejamentos instrucionais e trabalhando com os aprendizes a fim de garantir-lhes a aprendizagem.

Vários autores como Dörnyei (2001), Stipek (1998), Pintrich e Shunk (1996), Gardner e Mclntyre (1993) chegaram à conclusão de que a motivação do aprendiz é um processo antes mesmo de ser um produto, visto que não a observamos diretamente, mas a inferimos através de tarefas, esforços e verbalizações dos alunos. Dörnyei (2001) acrescenta 


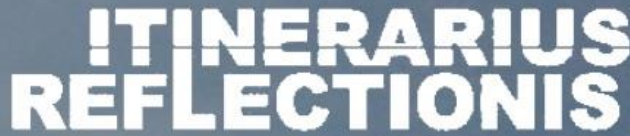

Revista Eletrônica de Graduação e Pós-Graduação em Educação

que a motivação do aluno não envolve apenas a sustentação do esforço exercido em uma determinada atividade, mas também sua amplificação. De acordo com o autor, quando as pessoas decidem fazer alguma coisa, a motivação é o elemento responsável por essa decisão e pelo investimento de tempo necessário para sustentar ou expandir a atividade.

Jacob (2002, p.39) explica que os teóricos consideram a motivação como um dos fatores mais importantes durante o processo de aprendizado de língua estrangeira, podendo influenciar o que, quando e como nós aprendemos. Para eles, a motivação sustenta uma relação entre aprendizagem e desempenho, na medida em que ela influencia os resultados, ou seja, a forma como o aluno aprende. Inversamente, também, o que o aluno aprende e o que ele faz para aprender influenciam a motivação. Portanto, quando um aprendiz alcança suas metas de aprendizagem, ele se sente capaz de aprender uma língua e isso o impulsiona sempre.

A partir dos estudos realizados, pode-se classificar a motivação em instrumental ou integrativa e ainda em motivação intrínseca ou extrínseca. Para Gardner e Lambert (1972 apud PIZZOLATO, 1995, p.44) a motivação instrumental revela as necessidades técnicas e/ou profissionais do aluno, tal como aprender um idioma para obter uma promoção profissional, ou seja, revela reconhecimento social. Já a motivação integrativa mostra o desejo do aluno em se integrar à cultura onde a língua-alvo é falada ou aos povos que falam o idioma que está sendo aprendido. Uma motivação não exclui a outra, podendo o aluno ser motivado por ambas.

Para Van Els et al. (1984, apud PIZZOLATO, 1995, p. 44), ambas as motivações, instrumental e integrativa, podem ser caracterizadas como intrínseca ou extrínseca. Essa distinção foi originalmente proposta por Deci e Ryan (1985). Para os autores, a motivação intrínseca é orientada nas expectativas e projeções do próprio aluno. Já a motivação extrínseca é marcada por estímulos externos, provenientes direta ou indiretamente de terceiros.

Já Viana (1990, p. 45) mostra três diferentes manifestações de motivação e os fatores que a influenciam. São elas: (1) motivação relacionada ao aprendizado de língua estrangeira, que se refere às atitudes do aluno em relação à língua-alvo; (2) motivação relacionada aos povos e países da língua-alvo, relacionada às atitudes e opiniões do aluno no que tange à cultura dos países da língua-alvo; (3) a motivação para a aula, que inclui ações, reações e atuações do aluno face ao conteúdo apresentado e aos procedimentos de ensino usados pelo professor.

Dörnyei (2001) relata que são muitos os fatores que influenciam a motivação de aprender dos alunos, por exemplo, a influência dos pais, do professor e do grupo. Os pais podem 


\section{IrTeparius REFLECTIONIS}

Revista Eletrônica de Graduação e Pós-Graduação em Educaçāo

determinar o comportamento do aluno, pois fazem com que seus filhos se espelhem em suas atitudes e ações em relação à língua-alvo. A influência dos professores pode ser separada em quatro dimensões inter-relacionadas: características pessoais dos professores; imediatismo do professor (immediacy), ou seja, comportamentos verbais e não-verbais dos professores que reduzem suas distâncias com os alunos; comportamento motivacional ativo socializador, dado por meio do planejamento, apresentação das tarefas, sistema de respostas/recompensas e gerenciamento da sala de aula.Por fim, o grupo pode também exercer impacto na motivação dos alunos, por exemplo, uma quantidade numerosa de alunos por sala, nível de instrução não adequado ou mudança frequente de professor.

Uma teoria que se faz importante para a discussão do conceito de motivação é a teoria da expectativa-valor, ou seja, quanto maior a expectativa de resultado positivo que o aprendiz tem para realizar uma atividade, e maior o valor de incentivo atribuído a este resultado, maior será sua motivação (LIMA, 2006). Dörnyei (2001b, p.24-25), baseando-se em Eccles e Wigfield (1995 apud DÖRNYEI, 2001), traz a definição de valor em forma de quatro componentes: 1) valor de realização de uma atividade; 2) valor intrínseco, interesse ou prazer em realizar a atividade; 3) valor da utilidade extrínseca ou consciência de como a tarefa relaciona-se com os objetivos; 4) custo, ou valor negativo - avaliação de esforço e tempo dedicado a uma ação e gastos emocionais, como ansiedade e medo de falha. Esses dois últimos elementos emocionais evidenciam o fracasso e deixa os indivíduos desmotivados, ou seja, aquela expectativa positiva que o aluno traz consigo pode se tornar algo negativo, fazendo seu desempenho diminuir durante a realização de uma tarefa.

O conceito de expectativa para a motivação está associado ao esforço, à ideia da possibilidade de alcançar objetivos e às habilidades para se chegar a esses objetivos (SHAABAN; GHAITH, 2000 apud LIMA, 2006, p. 150). Dörnyei (2001b), da mesma forma, correlaciona a motivação para aprendizagem de línguas ao termo expectativa com a possibilidade de êxito, associada à confiança do aluno e ainda à perspicácia de dificuldade das atividades, quantidade de esforço necessário e apresentação da atividade pelo professor. São expectativas que influenciam na motivação do aluno em aprender.

De acordo com os autores Scheib (1970), Oxford e Shearin (1996) e Pajares (1992 apud LIMA, 2006, p. 150), “a expectativa é como uma espécie de crença que age como um pensamento antecipatório e influencia a motivação do aluno para a aprendizagem de uma LE". Podemos inferir que essa expectativa caracteriza-se como uma motivação extrínseca devido a 


\section{IrTeparius REFLECTLNIS}

Revista Eletrônica de Graduação e Pós-Graduação em Educaçāo

incentivos externos, mas que, à medida que o aluno interioriza motivos para aprender uma língua, esses motivos assumem o valor de crença e tornam-se uma força estimuladora da aprendizagem (LIMA, 2006).

\section{METODOLOGIA}

A pesquisa empreendida enquadra-se no perfil de pesquisa qualitativa que tem por objetivo investigar em um determinado evento pedagógico a motivação inicial e as expectativas em relação à aprendizagem de alunos de nível iniciante de língua francesa. Como afirma Bogdane Biklen (1982 apud ALVAREZ, 2007, p. 207), a pesquisa qualitativa engloba a aquisição dos dados descritivos através de um contato direto do caso estudado com o pesquisador, dando maior ênfase ao processo que ao produto e se preocupando em revelar a expectativa dos participantes.

A pesquisa qualitativa firma-se dentro de uma prática interpretativista que, de acordo com Sevigny (1981, p.68), é capaz de "captar o que as pessoas dizem e fazem enquanto um produto de como elas interpretam a complexidade do mundo", esclarecendo então, que essa pesquisa procura descrever e analisar as motivações, expectativas e quiçá outros aspectos importantes dos participantes da pesquisa envolvidos numa prática e inseridos em um contexto real.

A pesquisa foi desenvolvida em um Centro de línguas de uma universidade pública do Estado de Minas Gerais. Os participantes da pesquisa foram 20 alunos de uma turma de língua francesa do Básico 1 (A1). Escolhemos uma turma de iniciantes na intenção de investigar a motivação que alunos apresentam para iniciar algo novo, ou seja, para começar os estudos de um novo idioma, nesse caso, a língua francesa. Pretendemos, com isso, verificar o que levou os alunos a procurarem o idioma, se foram razões instrumentais, integrativas, intrínsecas, extrínsecas ou outras.

Inicialmente, foi aplicado um questionário para traçar o perfil sociocultural dos alunos e suas respectivas motivações em relação à aprendizagem da língua francesa (por exemplo, o que os levou a iniciar o estudo dessa língua). O questionário foi escolhido como método para a coleta de dados por acreditarmos que os alunos poderão se sentir mais à vontade para expressar suas opiniões sobre o curso, se comparado à entrevista, por exemplo, e pelas vantagens em levantar opiniões e perspectivas. Como afirmam McDonough e McDonough 


\section{MTIFAR REFLETIONIS}

Revista Eletrônica de Graduação e Pós-Graduação em Educaçāo

(1997, p. 171-172 apud VIEIRA-ABRAHÃO 2010, p. 221), “o conhecimento que se necessita é controlado por perguntas, o que garante precisão e clareza; podem ser coletados em diferentes momentos e permitem respostas em diferentes locais". As perguntas do questionário visavam identificar motivações e expectativas dos alunos com relação à aprendizagem da língua francesa. Este questionário inicial foi bastante eficiente, pois permitiu a observação das tendências e reações relevantes dos alunos sobre as práticas de ensino da língua-alvo.

Para análise do conteúdo dos questionários, foram identificados pontos em comum nas respostas dos alunos, de acordo com a proposta de Gillham (2000). Para cada resposta do tipo aberta, foram grifadas as palavras recorrentes (palavras-chave que se repetiam) nas respostas dadas pelos alunos e levantadas categorias (temas), as quais foram baseadas nos tipos de perguntas que foram feitas, visando ao levantamento da motivação e das expectativas dos alunos em relação à aprendizagem da língua francesa.

\section{ANÁLISE E DISCUSSÃO DE DADOS}

Com base nesse apanhado teórico, discutiremos agora as expectativas e a motivação dos alunos participantes da pesquisa a partir da análise do questionário respondido por eles.

É sabido que os alunos já vão para as aulas com expectativas sobre como deve ser uma aula de língua estrangeira e o papel que o professor deve desempenhar durante o curso, com base em crenças que os alunos possuem sobre o processo de ensino e aprendizagem. Desse modo, é importante levantar as expectativas que esses alunos trazem para as aulas de língua, pois, como mostrou Jacob (2002), vários foram os teóricos que consideraram que a motivação em aprender é um fator que necessita ser sustentado para que os alunos consigam persistir na tarefa de aprender. A esse respeito, Lima (2006) aponta a importância da teoria da expectativavalor, proposta por Gardner e Tremblay (1995), ao afirmarem que quanto mais o aluno tem a expectativa de um resultado positivo em sua aprendizagem, maior será o valor atribuído a uma atividade, o que pode gerar repercussões em sua motivação, na medida em que essas expectativas são atendidas pelo professor e pelo curso. Como vimos, a expectativa atua no comportamento dos alunos como um pensamento antecipatório, e, quando é atendida, pode gerar mais motivação. 


\section{ITIERARIUS

De forma a identificar as expectativas dos alunos em relação ao curso de francês ofertado, uma das perguntas do questionário foi: "O que você espera aprender/aperfeiçoar neste curso"? As respostas revelaram que a maioria deseja desenvolver a compreensão oral, o que é compreensível, visto que no questionário muitos afirmam que almejam compreender e se comunicar com falantes da língua francesa.

Pensando na noção de expectativa de competência, parece que eles elencam a compreensão oral como atividade que querem desenvolver (que é uma habilidade receptiva), ao invés da fala (habilidade ativa e sempre considerada mais difícil) porque entendem que, no nível básico 1, é o que conseguirão desenvolver no semestre. O gráfico que se segue apresenta as habilidades que os alunos querem desenvolver, segundo dados do questionário inicial:

Gráfico 1: Habilidades que os alunos desejam trabalhar/aperfeiçoar nas aulas de LF

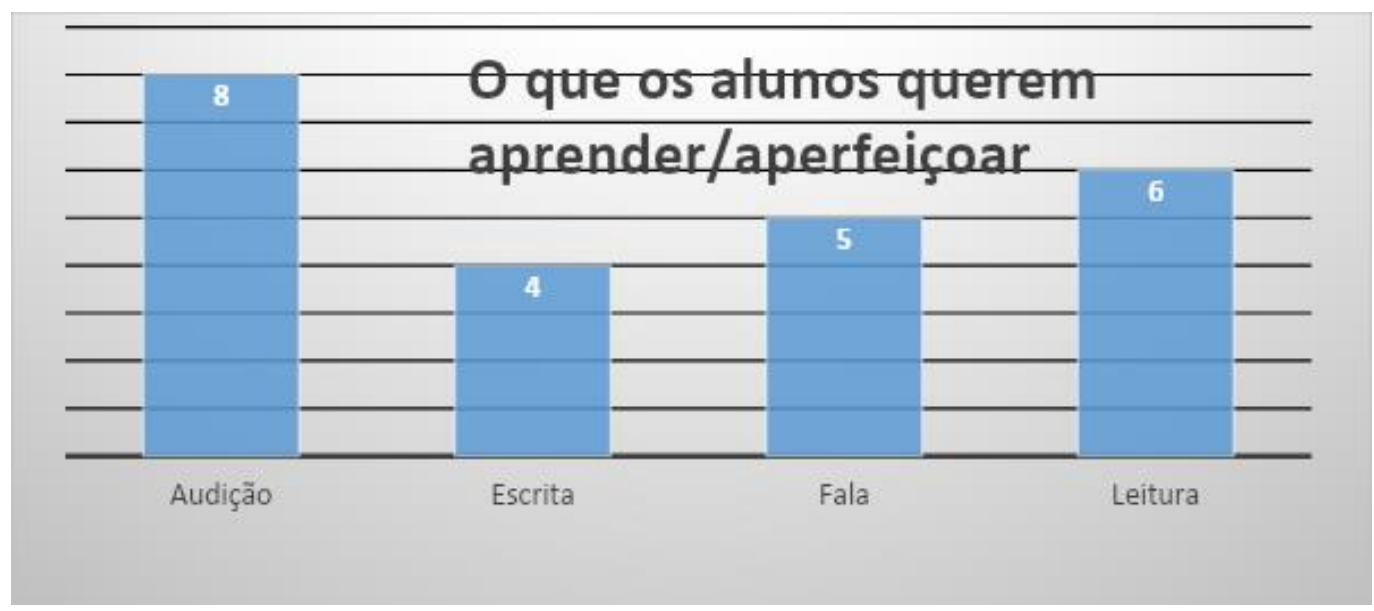

Fonte: elaboração própria

Os trechos a seguir, extraídos do questionário, comprovam esses dados que foram apresentados no gráfico 1 .

Excerto 1: "O que você espera aprender/aperfeiçoar neste curso"?

- Ter uma bagagem de francês excelente para comunicar com os franceses, e até mesmo fazer intercâmbio. (A01)

- Principalmente a fala e a audição. (A03)

- Espero aprender a língua no nível que dê para eu viajar, ler e ouvir músicas sem muita dificuldade além de aprender sobre a cultura francesa. (A04)

- Espero aprender o necessário para poder me comunicar com os fluentes na língua, e também praticar a fala, escrita e leitura. (A05)

- Aprender a entender e comunicar em francês. (A11) 


\section{ITHerarius REFLETIONIS}

Revista Eletrônica de Graduação e Pós-Graduação em Educação

As expectativas elencadas têm a ver com o fato de grande parte dos motivos que levaram muitos alunos a querer aprender a LF é o interesse em fazer mobilidade ${ }^{2}$. Esse interesse está associado à motivação instrumental e integrativa. Esta é compreendida como o processo das interações sociais mediadas pela linguagem, como foi explicitado no arcabouço teórico, ou seja, alunos interessados em aprender uma LE pelo desejo de se integrar à cultura da línguaalvo (GARDNER; LAMBERT, 1972) e aquela é entendida como a razão prática que os alunos apresentam para estudar a LF, ou seja, passar na avaliação oral realizada na universidade para conseguirem entrar no programa de mobilidade. O gráfico que se segue mostra essa incidência e outros motivos que os levam a aprender a LE em questão:

Gráfico 2: Motivos dos alunos para aprender a LF

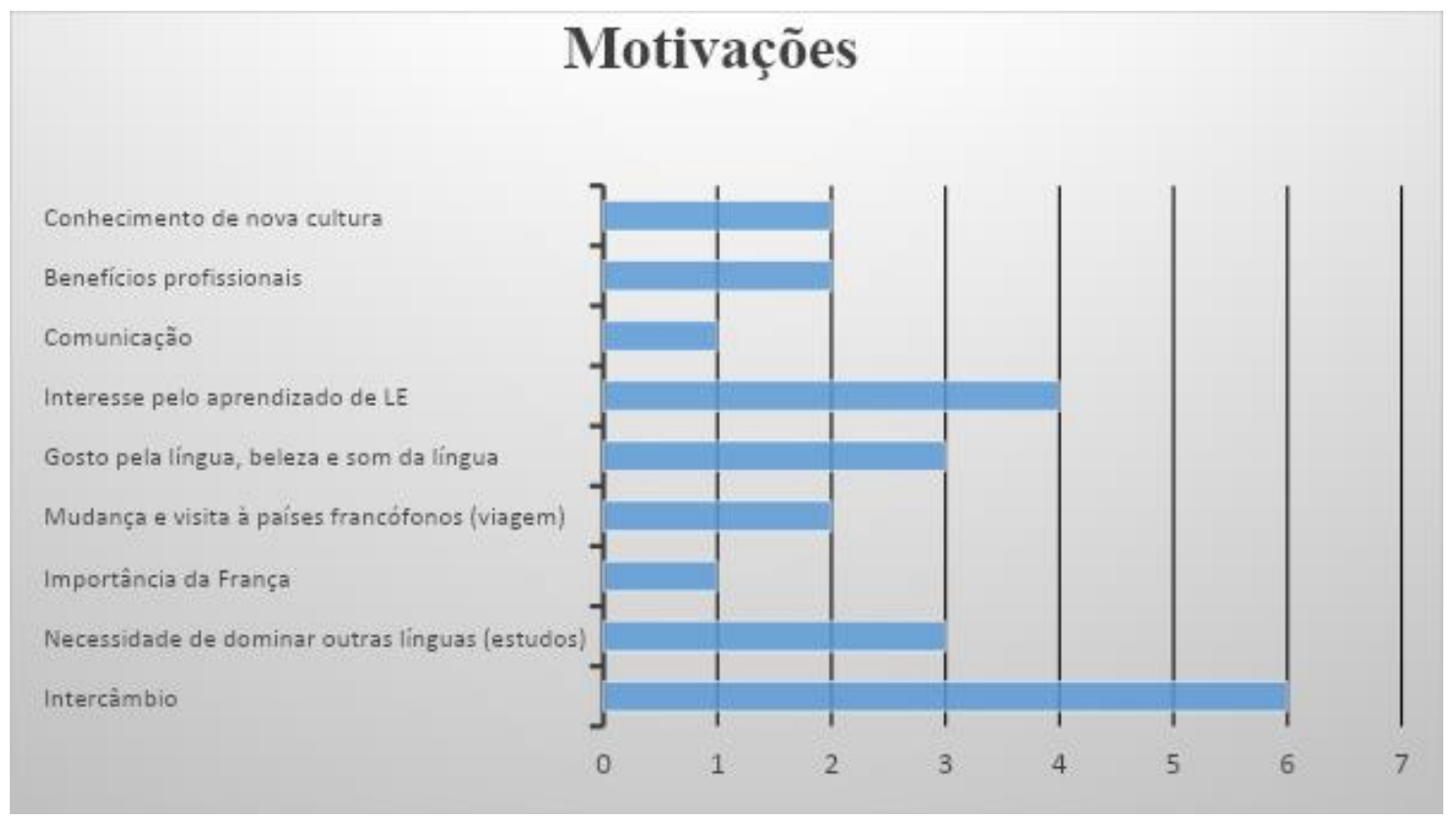

Fonte: elaboração própria

A partir desse gráfico, que apresenta as motivações dos alunos em aprender o francês como LE, não podemos deixar de ressaltar o fato de alguns alunos terem outros motivos além de realizar o intercâmbio, como por exemplo, o interesse pelo estudo de uma nova língua. Trata-se de um indício de motivação intrínseca, como proposto originalmente por Deci e Ryan (1985), a qual é orientada nas expectativas e projeções do próprio aluno.

\footnotetext{
${ }^{2} \mathrm{~A}$ mobilidade é um programa de incentivo vigente na universidade onde estudam que possibilita estender os estudos em universidades francesas.
} 


\section{ITHerarins REFLECTIONIS}

Revista Eletrônica de Graduação e Pós-Graduação em Educaçāo

Essas orientações integrativas, instrumentais e intrínsecas são confirmadas pelas respostas dos alunos no questionário, como notamos no excerto 2:

Excerto 2: “Que motivos te levaram a querer aprender a língua francesa?”

- Fazer intercâmbio e interesse pela língua. (A01)

- Possibilidade de intercâmbio e o conhecimento de uma nova língua. (A03)

- Quero fazer intercâmbio. (A05)

- Um possível intercâmbio na França. (A11)

- Procurar aprender uma nova cultura e participar de programas de intercâmbio. (A14)

O que também comprova a necessidade dos alunos em aperfeiçoar a audição (citada no gráfico 1) são as respostas dadas à pergunta sobre qual tipo de atividade eles consideram mais motivadoras para aprender o francês, estando no topo os exercícios de audição, seguidos dos exercícios de conversação. Esses itens nos levam a compreender que a motivação dos alunos, em grande parte, está centrada na compreensão da LF e na comunicação, habilidades essas que eles precisam desenvolver, caso desejem realizar estudos em um país de LF.

Gráfico 3: Atividades mais motivadoras segundo os alunos

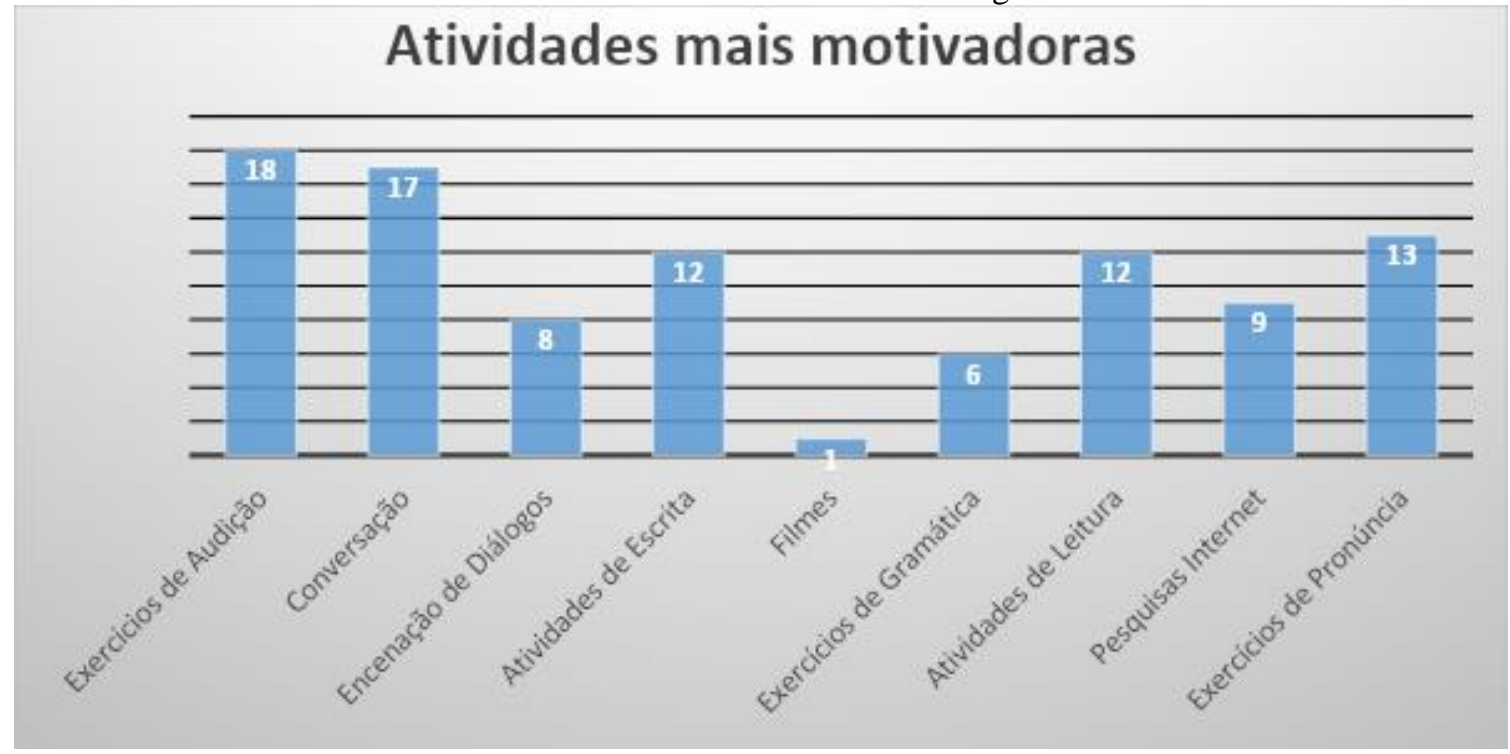

Fonte: elaboração própria

Indagamos também os alunos sobre as atividades que consideram menos motivadoras para a aprendizagem do francês. Em maior número, como podemos verificar no gráfico 4, estão os exercícios de gramática: 


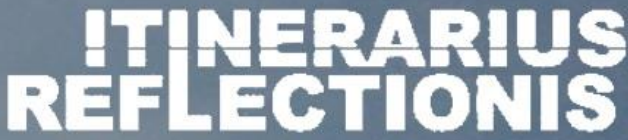

Revista Eletrônica de Graduação e Pós-Graduação em Educaçāo

Gráfico 4: Atividades menos motivadoras segundo os alunos

\section{Atividades menos motivadoras}

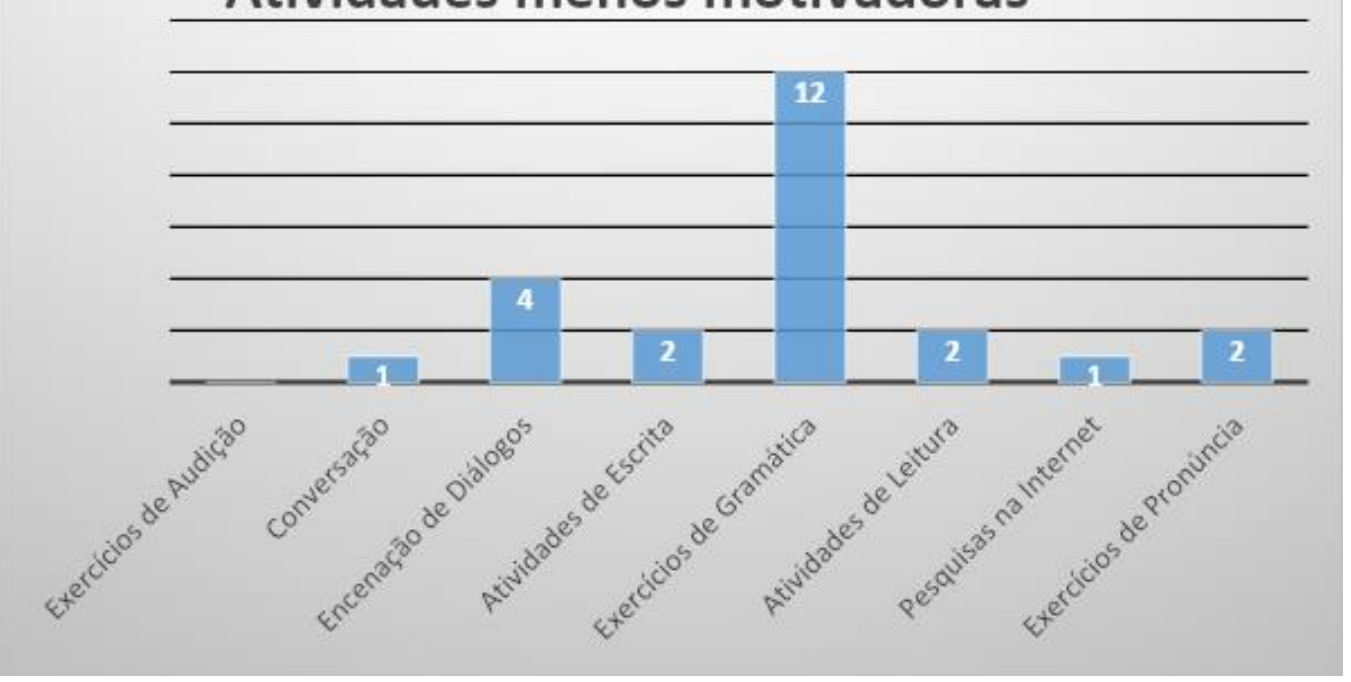

Fonte: elaboração própria

A encenação de diálogos é a segunda atividade apontada como menos motivadora para vários alunos. Entendemos que esses tipos de atividades, encenação de diálogos e exercícios de gramática, possam ser pouco motivadoras aos alunos por envolverem a manipulação "artificial" de formas ou frases prontas, o que pode ser entendido como cansativo e, ainda, temos uma possível interpretação de que pode ser devido ao fato de os alunos terem a crença de que não se aprende uma língua através da gramática.

Por fim, fizemos um levantamento das expectativas que o grupo tem sobre o que gostaria que fosse trabalhado pelo professor nas aulas. Assim, a tabela que se segue mostra os temas que mais lhes interessam, ou que eles acreditam ser importantes a serem desenvolvidos em sala de aula:

Tabela 1: Expectativas dos alunos sobre temas a serem trabalhados pelo professor

\begin{tabular}{|c|c|}
\hline Temas que os alunos gostariam que fossem trabalhados & Número de respostas \\
\hline Cultura & 12 \\
\hline História & 3 \\
\hline Turismo e viagens & 3 \\
\hline Expressões do dia a dia, vocabulário & 2 \\
\hline Temas variados & 1 \\
\hline Temas cotidianos no Brasil & 1 \\
\hline Economia & 1 \\
\hline Política & 1 \\
\hline Negócios & 1 \\
\hline Moda & 1 \\
\hline
\end{tabular}

Fonte: elaboração própria 
O tema mais citado pelos alunos é a cultura dos países francófonos. A partir disso, podemos reafirmar que esse desejo de aprender sobre a cultura francesa justifica-se pelos motivos que foram mais mencionados pelos alunos que os levaram a estudar a LF - o interesse em participar de um intercâmbio. Esse motivo, como sustenta Gardner e Lambert (1972), revela o anseio dos aprendizes de se integrar a uma outra cultura, à cultura da língua almejada, neste caso, à cultura francesa. É a chamada motivação integrativa, já discutida. É o que se pode perceber nos excertos que se seguem:

Excerto 3: "Quais temas (assuntos) você gostaria que o professor trabalhasse nas aulas? De que forma (como)"'?

- Cultura francesa, por meio de leituras. (A01)

- Assuntos da atualidade e relacionados a cultura de países que falem a língua francesa. (A03)

- Assuntos históricos, culturais até a atualidade. Com jogos, dinâmicas. (A11)

- Gostaria de saber um pouco mais sobre a cultura francesa, pode ser em forma de músicas, filmes e afins. Acredito ser também uma forma divertida de aprendizado. (A12)

- História, economia, política e cultura, creio que o uso de filmes e áudio seria de grande proveito para esta abordagem. (A15)

A análise das respostas dos 20 participantes da pesquisa ao questionário inicial mostram que a motivação para aprender a LF era bastante alta, pois havia uma expectativa de sucesso na aprendizagem, um sentimento de curiosidade e, ainda, a presença de componentes motivacionais externos que estão relacionados ao desejo de interagir socialmente com falantes da língua em foco (BROWN, 1994). Como mencionado anteriormente, grande parte dos motivos que levaram esses alunos a querer aprender a LF foi a possibilidade de participarem da mobilidade em um país francófono e o interesse pelo estudo de uma nova LE.

A partir desse questionário inicial, podemos afirmar, portanto, que há indícios de fatores motivacionais extrínsecos e intrínsecos, tanto instrumentais quanto integrativos, conduzindo a motivação inicial desses alunos a fim de aprender a LE em questão.

\section{CONSIDERAÇÕES FINAIS}

É importante que professores pesquisem sobre o ensino de línguas estrangeiras e usem as teorias e as pesquisas realizadas nessa área como uma base para a reflexão crítica sobre os processos de aprender e ensinar. A reflexão sobre motivação e expectativas pode nos conduzir a mudanças em relação às nossas ações didático-pedagógicas para oferecer um ensino de qualidade, respondendo aos desejos dos nossos alunos. 
Uma percepção importante no campo dos estudos sobre a aprendizagem de língua estrangeira foi que a motivação é muito importante para a verdadeira aprendizagem. Ela é considerada, ainda, a chave para o sucesso na aquisição de uma língua estrangeira (DÖRNYEI, 2001; NOELS et al., 1999; OXFORD; SHEARIN, 1994).

Em síntese, a presente pesquisa baseou-se em estudos teóricos sobre motivação em estudar uma LE. Os resultados obtidos trouxeram implicações relevantes para o ensino e aprendizagem de LF no que tange ao conhecimento, por parte dos professores, da existência de fatores que têm influência na dinâmica motivacional do aluno, tais como o respeito às diferenças individuais e culturais, o humor, a empatia, o tratamento beneficiando a igualdade dos alunos por parte dos professores, essenciais para influenciar a motivação deles (VIAU, 2004).

\section{REFERÊNCIAS}

ALVAREZ, M. L. O. Crenças, motivações e expectativas de alunos de um curso de formação Letras/Espanhol. In: ALVAREZ, M.L.O; SILVA, K.A. (orgs.) Linguística Aplicada: múltiplos olhares. Brasília: Unb/Finatec; Campinas: Pontes Editores, 2007, p.191-231.

BROWN, D. H. Principles of language learning and teaching. 3rd ed. Prentice Hall Regents, 1994.

DECI, E. L.; RYAN, R. M. Intrinsic motivation and self-determination in human behavior. New York: Plenum, 1985.

DÖRNYEI, Z. Teaching and Researching Motivation. England: Longman, 2001a.

New Themes and aproaches in Second Language Motivation Research. Annual Review of Applied Linguistics. Cambridge: Cambridge University Press, 2001b, p. 43-61.

GARDNER, R. C.; LAMBERT, W. Attitudes and motivation in second language learning. Rowley, MA: Newbury House Publishers, 1972.

.; MACINTYRE, P. D. A student's contributions to second-language learning. Part II: Affective variables. Language Teaching, v. 26, n. 01, 1993, p. 1-11.

.; TREMBLAY, P. F. Expanding the motivation construct in language learning. The Modern Language Journal, v. 79, 1995.

GILLHAM, B. Case study research methods. London: Continuum, 2000.

JACOB, L. K. Diferenças motivacionais e suas implicações no processo de ensino/aprendizagem de espanhol como língua estrangeira. Dissertação de Mestrado.São José do Rio Preto: UNESP, 2002. 
LEFFA, V. J. Metodologia do ensino de línguas. In: BOHN H. I; VANDRESEN, P. Tópicos em linguística aplicada: o ensino de línguas estrangeiras. Florianópolis: UFSC, 1988, p. 211 236.

LIMA. S. S. Crenças e expectativas de um professor e alunos de uma sala de quinta série e suas influências no processo de ensino e aprendizagem de inglês em escola pública. In: BARCELOS, Ana Maria F.; VIEIRA-ABRAHÃO, Maria Helena (Orgs.). Crenças e ensino de línguas: foco no professor, no aluno e na formação de professores. $2^{\mathrm{a}}$ ed. Campinas, SP: Pontes Editores, 2006, p. 147-162.

NOELS, K A., CLEMENT, R., \& PELLETIER, L. G. Perceptions of teacher communicative style and students' intrinsic and extrinsic motivation. Modern Language Journal, 83, 1999, p. 23-34.

OXFORD, R. New pathways of language learning motivation. In: Language learning motivation: pathways to the new century. University of Hawii, 1996,p. 1-8.

SHEARIN. Language learning motivation in a new key. In: Language learning motivation: pathways to the new century. University of Hawii, 1996,p. 121-144.

PINILLOS, J. L. Princípios de psicologia. Madrid: Alianza Universidad, 1975.

PINTRICH, P.R.; SCHUNK, D.H. Motivation in education: theory, research, and applications. Englewood Cliffs, New Jersey: Prentice Hall, 1996.

PIZZOLATO, C. E. Características da construção do processo de ensino e aprendizagem de língua estrangeira (inglês) com adultos da terceira idade. Dissertação de Mestrado. Campinas: UNICAMP, 1995.

SCHEIB, K. E. Beliefs and Values. New York: Holt, Rinehar and Winston, 1970.

SEVIGNY, M. J. Triangulated inquiry: a methodology for the analyses of classroom interaction. In: The School of Art. [S. 1.]: Bowling Green State University, 1981.

STIPEK, D. Motivation to learn: from theory to practice. Los Angeles: Universidade da Califórnia, 1998.

VIANA, N. Variabilidade da motivação no processo de aprender língua estrangeira na sala de aula. Dissertação de Mestrado. Campinas: UNICAMP, 1990.

VIAU, R. La motivation: condition au plaisir d'apprendre et d'enseigner en contexte scolaire. 3e Congrès des chercheurs en Éducation Bruxelles, mars 2004.

VIEIRA-ABRAHÃO,M.H. Metodologia na investigação das crenças. In: BARCELOS, Ana Maria F.; VIEIRA-ABRAHÃO, M. H. (Orgs.). Crenças e ensino de línguas: foco no professor, no aluno e na formação de professores. $2^{\mathrm{a}}$ ed. Campinas, SP: Pontes Editores, 2010, p. $219-231$. 